\title{
Energy modelling and decision support algorithm for the exploitation of biomass resources in industrial districts
}

\author{
Riccardo Zaccone ${ }^{1 *}$, Roberto Sacile ${ }^{1}$, Marco Fossa ${ }^{2}$ \\ ${ }^{1}$ Department of Informatics, Bioengineering, Robotics and Systems Engineering, University of \\ Genova, Via Opera Pia 13, 16145 Genova, Italy \\ ${ }^{2}$ Department of Mechanical, Energy, Management, and Transportation Engineering, University of \\ Genova, Via Opera Pia 15, 16145 Genova, Italy \\ Email: ric.zaccone@gmail.com
}

\begin{abstract}
European energy policies drive to energy efficiency and renewable energies. This global view, converted into national regulations, finds difficulties with energy market, technology costs, and mutable economic conditions making difficult the evaluation of the profitability of these projects. Based upon the above considerations, a Decision Support System for the evaluation of the sustainability of Biomass Combined Heat and Power (BCHP) Plants is here presented. The model provides a technical-economic quantification of a CHP Plant supplied by biomass, with Rankine thermal cycle and District Heating (DH) network serving an industrial district. The aim of the model is to find the optimal Plant configuration in terms of steam turbine choice and the consequent thermal cycle parameters by varying decisional variables describing the type of industrial district, its yearly thermal loads (heating and cooling), the requested carrier fluid, the pipeline distances from the Power Plant. Other parameters, as the feed-in-premium tariff for the electrical energy and natural gas integration, have been considered. Starting by variable and fixed costs and revenues, the Internal Rate of Return of the project has been calculated. An optimal Plant configuration has been defined, and a sensitivity analysis have been performed. The model has been applied to a case related to the city of Quattordio in northern Italy.
\end{abstract}

Keywords: Biomass, Cogeneration, District Heating, CHP Plant, Optimization.

\section{INTRODUCTION}

The European Union energy policies aim at ensuring a reliable provision of energy in any moment, providing at the same time a competitive environment with affordable prices, while lowering the greenhouse gas emissions, pollution, and fossil fuel dependence [1]. To pursue these goals and to maintain the European energy consumption sustainable, a coherent long-term strategy has been formulated, including targets for the years 2020, 2030, and 2050. The 2020 Energy Strategy [2] defines the EU energy priorities between 2010 and 2020: a reduction in greenhouse gases by at least $20 \%$, an increase of renewable energy fraction in the EU energy mix to at least $20 \%$, an increase of energy efficiency by at least $20 \%$. Among the EU energy priorities at 2030 defined in the 2030 Energy Strategy [3], the following EU targets can be quoted: a reduction of at least a $40 \%$ in greenhouse gas emissions, compared to 1990 ones, and a mandatory target of at least $27 \%$ of renewable energy in the EU. Finally, the EU objectives by 2050 [4] are to achieve $80 \%$ to $95 \%$ reduction in greenhouse gases compared to 1990 levels.

The Italian National Energy Strategy [5] includes important structural interventions, aiming at addressing challenges as the supply security, now especially critical concerning peak loads. Moreover, also due to the high dependence on imported fossil fuels, the energy prices in Italy are generally higher than in other European countries, both for citizens and companies. For the reasons above, the National Strategy focuses on main targets, in order to achieve and overcome the "20-20-20" package, and to continue supporting the development of renewable (including biomass) sources.

Among the National regulations boosting renewable resources, the Ministerial Decree of 6 July 2012 establishes new procedures for supporting electricity generation by renewable energy sources (RES-E) plants (other than photovoltaic ones) with a capacity of at least $1 \mathrm{~kW}$. The support consists in the application of feed-in-premium incentives to new, totally rebuilt, reactivated, repowered/upgraded or renovated plants, which have been commissioned after the 1st January 2013 [6]. The Ministerial Decree of 23 June 2016 integrated and updated the previous Decree [7].

In this context, the Combined Heat and Power (CHP) generation has been recognized as a thermodynamically efficient method of energy conversion, [8]. 
National Regulation moved towards the cogeneration incentive through the Ministerial Decree of 4th August 2011 [9], replacing and integrating the Annexes of the Decree no. 20/2007 that implemented Directive 2004/8/EC [10] about CHP promotion. The Decree defines the calculation method for the recognition of high efficiency cogeneration systems.

For an economic assessment of a CHP system, it is mandatory to define a complete methodology that takes into account all relevant decision variables, with a proper costbenefit analysis, including investment, operation, maintenance and environment costs [11].

A traditional design method includes an initial evaluation of the thermodynamic and technical performance of the system, as described for example in [12] and [13]. Once the feasible solutions have been identified, the associated costs are estimated to determine the profitability of the investments. The final design is usually obtained by carrying out a design parameters sensitivity analysis to improve energy and/or economic performance using an iterative strategy. Constraints, as limits on the environmental resources needed for plant operation or restrictions imposed by the pollutant emissions, may reduce the ranges of feasible values for the design parameters [14].

The selected technology for this analysis is the superheated steam Rankine cycle, composed by steam turbine and biomass steam generator, CHP Plant and District heating lines.

Several authors treated different aspects of this plant configuration.

A first approach is to study the components and the generic power plant cycle and optimize the energy efficiency. Numerical modelling is widely used in industry, for example for detailed understanding of the combustion process. Rajh et al. [15] presented a numerical study of a $13 \mathrm{MWth}$ waste wood-fired grate boiler, based on the coupled in-bed fuel conversion modelling and freeboard combustion modelling methodology. Gebreegziabher et al. [16] studied the heat integration between the steam power plant and the drying process, performed by a biomass powerplant that burns empty fruit bunches. Cimdina et al. [17] performed the analysis of operating conditions of a biomass cogeneration plant in Jelgava using woodchip, obtaining empirical equation by regression analysis.

A different approach consists in optimizing the biomass exploitation in a particular area of interest. Shabani and Sowlati [18] presented the supply chain configuration of a typical forest biomass power plant and developed a dynamic optimization model to maximize the overall value of the supply chain. Freppaz et al. [19] developed a decision support system for forest biomass exploitation for energy production purposes. It consists in integrating geographic information system (GIS) based techniques with mathematical programming methods to yield a comprehensive system that allows the formalisation of the problem, the decision taking, and the evaluation of effects.

A more complete approach consists on providing both technical and economical evaluations. Ferreira et al. [20] presented a model based on a cost-benefit analysis used to design an optimal cogeneration system for small-scale building applications, considering the Portuguese context. Mohan and El-Halwagi [21] worked with the purpose of addressing the utilization of biowaste or biomass source in a processing facility for combined heat and power (CHP). Voicu and Dimitriu [22] developed a mathematical model to determine the technical and economic effectiveness of the cogeneration implementation based on a net present value criterion, calculating the limit value of two parameters: the green certificate unit value and the cost of biomass per unit ton. Tereshchenko and Nord [23] studied energy supply plants associated with new or existing district heating (DH) systems, considering three highly efficient energy conversion technologies (biomass CHP plants included), considering the economic aspects and the technical limitations of the technologies. Delmastro et al. [24] analysed the benefits and the feasibility of a woody biomass cogeneration plant in Luserna San Giovanni (Torino, Italy), including the prefeasibility analysis of the district heating network. The study was supported by a GIS-based tool (Geographical Information System), evaluating the environmental and economic impacts of the biomass plant and of the connection to the district heating network on a short and long term horizon. Sartor et al. [25] presented a very interesting study using only simple models for thermodynamic, combustion process, heat transfer and finance, covering the whole supply chain from the production to the transport of the energy. Taking into account the specific profile of the heat demand, they provided accurate estimations of economic, environmental and energetic performances of CHP plants connected to district heating networks.

The subject of the present study is the economic optimization of a biomass CHP plant project, based on a Rankine superheated steam cycle, with a District Heating network serving industrial and civil thermal users. The analysis involves a wide range of know-how, including European, national and local regulations and policies, energy market and utility prices, thermodynamics and operation and Maintenance knowledges, performance analysis notions, district heating line design etc.

The present study is based on a specific case study of CHP plant project located in Quattordio, Italy but the present model can be applied to general cases, where biomass is burnt for feeding a cogeneration unit and a district heating network.

The purpose is to create a model for the technical-economic simulation of the CHP Plant, with the goal of optimizing the configuration that maximizes the final economic results of the project, by considering investment costs, variable costs and revenues, and by changing decisional variables. The model has been applied to the Quattordio Project, and the decisional variables have been individuated among the parameter treated during the Due Diligence phases.

\section{MODEL FORMALIZATION}

\subsection{Problem description}

In this work, starting by the case study experience and focusing on the Due Diligence feedback about economic indicator failures, the main indicator of the technicaleconomic feasibility of the Power Plant was found to be the Internal Rate of Return (IRR). In order to define the decision variables for the selected case study and problem family, we should consider the level reached by the project in the Authorization Process and the related constraints. The nominal size of the Power Plant was defined, in term of Rankine thermal cycle, nominal maximum gross electrical power producible by the steam turbine and maximum nominal values for the emissions of pollutants. 


\subsection{Decision variables}

Several parameters affect the technical and economic feasibility of a Biomass CHP Plant Project associated to a DH network; among them, this study focalizes on the main drivers on the investor choices.

In particular, the model could select which steam turbine has to be implemented in the thermal cycle among the steam turbine available, which user has to serve among a total number of potential thermal users with DC network, which carrier fluid among a set of available fluids, which user needs also cooling provided by means of absorption machines.

The variables can be defined as follows:

- $\delta_{i, f}$ is a binary variable that is equal to 1 if the $i$-th thermal user is served by the $f$-th fluid;

- cold $_{i}$ is a binary variable that is equal to 1 if the $i$-th thermal user is served by cooling energy service;

- $\tau_{t}$ is a binary variable that is equal to 1 if the $t$-th steam turbine has been chosen.

\subsection{The objective function}

The objective function is the Internal Rate of Return (IRR) of the Project, that is the "annualized effective compounded return rate" or rate of return that sets the net present value (NPV) of all cash flows (both positive and negative) from the investment equal to zero. The IRR has to be maximized. The equation formalizing this calculation is:

$$
N P V=\sum_{y=1}^{Y} \frac{N_{y}}{(1+I R R)^{y-1}}=0
$$

where $N_{y}$ is the Net Cash Flow for the $y$-th year, and $\mathrm{Y}$ is the total number of year, equal to 22 for these projects, including two years of construction and twenty years of operation (estimated lifetime of the Power Plant).

The Net Cash Flow is defined as follows:

$$
N_{y}=-E Q U_{T O T, y}+C A S H_{F I N, y}+C A S H_{O P E, y}
$$

The first term represents the Equity Funding; for these projects, it is supposed to represent about the $30 \%$ of the gross investment costs of the Power Plant, and is divided 50\% in the first year $(\mathrm{y}=1)$ and $50 \%$ in the second year $(\mathrm{y}=2)$, while it is equal to 0 for $y>2$. In this term all the investment costs are included.

The second term represents the Cash Flow from Financial activities, including mainly the repayment of the percentage of investment costs not funded as equity.

The third term represent the Cash Flow from Operations, which mainly includes Operating costs, Revenues and Taxes.

For the sake of brevity, the model description part of the economic calculation will be omitted.

\subsection{Net cash flow calculation}

The main terms composing the Net Cash Flow are analysed in the following, divided in different calculation areas.

\subsubsection{District Heating network}

For each thermal user, the following data are available: the existing power plant producing thermal energy for heating or process needs, the actual fuel consumptions and, for industrial users, a timetable of work shifts. Starting from this information, for each user, the thermal demand over the solar year has been divided into 48 average thermal powers $P t 1_{D, i, m}$ and $P t 1_{N, i, m}$, representing respectively the daily and night average thermal power requested by the user $i$, in the period $m$ ( 24 values each).

Furthermore, for each user, cooling demand over the solar year has been divided into 48 average cooling powers $P f_{D, i, m}$ and $P f_{N, i, m}$, representing respectively the daily and night average cooling power requested by the user $i$, in the period $m$ (24 values each).

The total daily thermal power requested by the $i$-th user, in the period $m$, by the fluid $f$, is defined by the following equation:

$$
P t_{D, i, m, f}=\left(P t 1_{D, i, m}+\frac{P f_{D, i, m}}{C O P_{i}} \cdot \operatorname{cold}_{i}\right) \cdot \delta_{i, f}
$$

The same equation is valid for the night thermal powers (subscript $N$ instead of $D$ ). COP is the Coefficient of Performance of the absorption chiller installed at the $i$-th user.

For each carrier fluid available, the main thermodynamic proprieties and parameters defining the DH design have been assigned, i.e. the delivery and return temperatures, pressures, density and enthalpy, and reference fluid velocity in the network pipes.

Once defined the thermal request, the DH network must be sized. A linear development of the DH line is considered, thus defining a main network divided in sections $\operatorname{Sec} D_{d}(d$-th section), and network branches $\operatorname{Sec}_{i}$ ( $i$-th user), whose values are assigned once defined the relative position between Power Plant and users.

To define the thermal losses to the surrounding ground, a matrix composed by the binary coefficients $a_{i, d}$ has been assigned, where the coefficient is equal to 1 when the $d$-th section is used to serve the $i$-th user.

In order to design the $\mathrm{DH}$ line, we introduce the following terms:

$P t_{\text {LOSS,DEL,f }}^{\prime}$ : Thermal power per unit length exchanged with the ground in the delivery line by the fluid $f$;

$P t_{\text {LOSS }, R E T, f}^{\prime}$ : Thermal power per unit length exchanged with the ground in the return line by the fluid $f$;

$S F$ : Safety Factor, considering thermal power peaks.

In addition to the above quantities, the Cumulative Length is defined as follows, representing the total length of the f-th fluid network downstream the d-th network node:

$$
\operatorname{Lcum}_{f, d}=\sum_{x=d}^{d \max }\left[\operatorname{Sec} D_{x} \cdot \operatorname{MAX} X_{i}\left(\delta_{i, f} \cdot a_{i, x}\right)\right]+\sum_{i=1}^{i \max }\left[\operatorname{Sec} L_{i} \cdot \delta_{i, f} \cdot a_{i, d}\right]
$$

where dmax and imax depend on the total number of main section and thermal users.

The DH is designed by calculating the diameter of each section pipe with the following equations: 
$\phi_{D E L, d, f}=1000 \cdot \sqrt{4 \cdot \frac{S F \cdot P t_{M A X, d, f}+\left(P t_{L O S S, D E L, f}^{\prime}+P t_{L O S S, R E T, f}^{\prime}\right) \cdot \operatorname{Lcum}_{f, d} / 1000}{\rho_{D E L, f} \cdot \pi \cdot v_{D E L, f} \cdot\left(h_{D E L, f}-h_{R E T, f}\right)}}$

$\varphi_{R E T, d, f}=\varphi_{D E L, d, f} \cdot \sqrt{\frac{\rho_{D E L, f} \cdot v_{D E L, f}}{\rho_{R E T, f} \cdot v_{R E T, f}}}$

$\phi_{D E L, i, f}=1000 \cdot \sqrt{4 \cdot \frac{S F \cdot P t_{M A X, i, f}+\left(P t_{L O S S, D E L, f}^{\prime}+P t_{L O S S, R E T, f}^{\prime}\right) \cdot \operatorname{SecL}_{i} * \delta_{i, f} / 1000}{\rho_{D E L, f} \cdot \pi \cdot v_{D E L, f} \cdot\left(h_{D E L, f}-h_{R E T, f}\right)}}$

$\varphi_{R E T, i, f}=\varphi_{D E L, i, f} \cdot \sqrt{\frac{\rho_{D E L, f} \cdot v_{D E L, f}}{\rho_{R E T, f} \cdot v_{R E T, f}}}$

where $P t_{M A X, d, f}$ is the maximum value of the thermal power requested downstream the section $\operatorname{Sec} D_{d}$.

The total cost of the DH network, input of the Equity Funding, is defined as follows:

$$
\begin{aligned}
& C_{D H}=A U X 1 \cdot C_{D H, F i x}+\sum_{f=1}^{f \max } \sum_{d=1}^{d \max } \operatorname{Sec} D_{d} \cdot\left[c u_{D H, D E L, d, f}\left(\varphi_{D E L, d, f}\right)+c u_{D H, D E L, d, f}\left(\varphi_{R E T, d, f}\right)\right]+ \\
& +\sum_{f=1}^{f \max } \sum_{i=1}^{i \max } \operatorname{Sec} L_{i} \cdot\left[c u_{D H, D E L, i, f}\left(\varphi_{D E L, i, f}\right)+c u_{D H, D E L, i, f}\left(\varphi_{R E T, i, f}\right)\right]
\end{aligned}
$$

where

$A U X 1 \cdot C_{D H, F i x}$ : fixed cost of the $\mathrm{DH}$ network;

$c u_{D H, D E L, d, f}\left(\varphi_{D E L, d, f}\right)$ : variable cost of the DH network, per unit length of delivery pipe, for the section $\operatorname{Sec}_{d}$ and fluid $f$; this value is a quadratic function of the pipe diameter, and the coefficient of the curve, here omitted, has different values for the different carrier fluids and has been obtained by regression from DH line supplier data sheets, historical data and literature indications. The same definition and calculation have been applied to each return pipe and section $S e c L_{i}$.

The cost of the absorption machines is calculated as the sum of each absorption machine cost considering all the users.

\subsubsection{Choice of the turbine and performance calculation}

In a biomass CHP, the steam is generated by means of biomass combustion, and it feeds a steam turbine coupled to an electric generator (gross electrical output). The energy produced is introduced into the national grid, net of selfconsumption of the Plant. Moreover, a fraction of the generated steam can be extracted to supply the district heating network and balancing the thermal cycle. As previously mentioned, in order to respect the constraints defined by the Authorization procedure, the cycle could be optimize maintaining the same condition at the steam generator and guarantying a nominal gross electrical power equal the authorized value.

With these assumptions, a cycle optimization has been performed by considering alternative solutions in the steam turbine choice, changing supplier (i.e. costs and performance) and steam thermodynamic proprieties at the extraction. The steam inlet conditions are maintained constant for each turbine, and mass and energy balances have been evaluated. The steam flow rate extracted from the turbine can vary between a minimum (operation of the cycle in Full Electric mode, when the gross electrical power is equal to the nominal value), and a maximum. The maximum steam extracted corresponds to the upper technical limit provided by the turbine supplier to avoid damages to the blading, and itis associated to the maximum thermal power that can be supplied to the users and the minimum gross electric power producible (operation in Full Cogeneration mode). There are infinite possible operating modes, comprised between the two limits, thus a function (per each turbine), between the gross electric power and the thermal power (provided by the biomass) to the DH network ( $P t_{B I O}$, $\left.P e_{G R O}\right)$ must be defined and provided in the form of curves or quadratic expressions obtained by regression.

Once chosen the steam turbine, for each daily and night period $m$, the value of the thermal power requested to the Plant is calculated as:

$$
\begin{gathered}
P t_{D H, D, m}=\sum_{i=1}^{i \max } \sum_{f=1}^{\max } P t_{D, i, m, f}+\sum_{f=1}^{f \max } \frac{P t_{L O S S, D E L, f}^{\prime}+P t_{\text {LOSS }, R E T, f}^{\prime}}{1000} \cdot \text { Lcum }_{f, 1}+ \\
+\sum_{i=1}^{i \max } \sum_{f=1}^{f \max }\left(\frac{P t_{L O S S, D E L, f}^{\prime}+P t_{\text {LOSS }, R E T, f}^{\prime}}{1000} \cdot \delta_{i, f} \cdot \operatorname{Sec} L_{i}\right)
\end{gathered}
$$

The corresponding gross electrical power is associated by means of the following equation:

$$
P e_{G R O, D, m}=\text { Coeff } 1 \cdot P t^{2}{ }_{B I O, D, m}+\text { Coeff } 2 \cdot P t_{B I O, D, m}+\text { Coeff } 3
$$

where the term $P t_{B I O, D, m}$ represents the thermal power provided to the DH line by the biomass cycle, equal to:

- $\quad 0$ if the biomass cycle stopped for maintenance

- $\quad P t_{D H, D, m}$ if $P t_{D H, D, m} \leq P t_{B I O, D, m, M A X}$

- $\quad P t_{B I O, D, m, M A X}$ if $P t_{D H, D, m} \geq P t_{B I O, D, m, M A X}$

The same equations hold for night thermal power (subscript $N$ instead of $D$ ).

The integration to the thermal power request is provided by natural gas boilers. The type, number and costs of the integration boilers depend on the decisional variables, such as the carrier fluids, the maximum thermal power requested and the maximum thermal power providable by the biomass cycle.

The model introduces the amount of hours per each period $m$, respectively in the daily and night periods $\left(h_{D, T O T}, h_{N, T O T}\right)$, and divides each period between operating and stops hours $\left(h_{D, B I O}, h_{N, B I O}, h_{D, G A S, S T O}, h_{N, G A S, S T O}\right)$.Then, the model multiplies each thermal power to the corresponding number of hours, and sum the terms obtained over the entire solar year, to obtain the total yearly thermal energy requested by the Plant $\left(E t_{D H}\right)$. Finally, it is possible to divide the total values into biomass ( $\left.E t_{B I O}\right)$ thermal energy and natural gas boilers $\left(E t_{G A S}\right)$ thermal energy, total gross electric energy produced ( $\left.E e_{\text {GRO }}\right)$, and net energy ( $\left.E e_{N E T}\right)$, applying a defined percentage of selfconsumptions (SC).

\subsubsection{Electric and Thermal energy tariffs}

The Electric energy tariff is defined by the MD 06.07.12 [6], according to the following equation:

$T_{e l}=T_{\text {base }}+T_{p r 1}+T_{p r 3}+T_{p r 3}=T_{f i x}+T_{C A R}$

Summarizing, the Decree assigns to this kind of Power Plants a base tariff plus additional prizes: among these prizes only the CAR (High Efficiency Combined Heat and Power) 
prize is variable and depends on the thermal cycle performance. For the sake of brevity, the calculation of the prize is here omitted. Moreover, synthetizing the procedure, the Decree divides the actual Plant into virtual plants, where the virtual High Efficiency CHP plant is defined by an overall efficiency equal to the reference value of $80 \%$. The Decree calculates which percentage over the gross electrical yearly production could be assigned to the High Efficiency CHP part. Finally, the final prize is obtained by multiplying this value to the maximum CAR prize value.

The thermal energy tariff for DH services can be defined using different approaches; in this study, a tariff value for each type of carrier fluid has been defined, distinguishing between industrial or civil thermal user. The total tariff, for each thermal user, is defined as follows:

$T_{t h, i}=T_{t h, n, i}+T C$

where $T_{t h, n, i}$ is the net tariff, paid by the thermal user, while $T C$ is the tax credit for the users served by $\mathrm{DH}$ supplied by biomass, equal to about $25.6 € / \mathrm{MWh}$ of thermal energy.

Thermal and electric tariffs, applied to the thermal energies requested and to the net electrical energy produced, define the main Plant revenues, parts of the Cash Flow from Operations introduced in Chapter 2.3.

\subsubsection{Model implementation}

The model as described below, has been implemented in three different software and approaches, including Lingo 9.0 but present results refer to an excel optimum search driven by a quite simple VBA routine able to perform the combination of decisional variables (about 300000 combinations) and to find the best variable set.

\section{CASE STUDY AND RESULTS}

\subsection{Case study main data}

\subsubsection{Thermal users and carrier fluids}

The model, as formalized in the previous Chapter, has been applied to the Project of the CHP Plant of Quattordio (Piedmont region, Italy).

The total number of thermal users imax is equal to 9,5 industrial and 4 civil users; three industrial users ( $i$ equal to 3,4 and 5) could request also cooling.

Table 1. Carrier fluids list

\begin{tabular}{|c|c|c|c|c|c|c|c|c|}
\hline & $p_{d e l, f}$ & $T_{d e l, f}$ & $T_{\text {ret }, f}$ & $\rho_{d e l, f}$ & $\rho_{\text {ret }, f}$ & $v_{d e l}$ & $\boldsymbol{h}_{d e l, f}$ & $h_{\text {ret }, f}$ \\
\hline$f$ & [bar] & {$\left[{ }^{\circ} \mathrm{C}\right]$} & {$\left[{ }^{\circ} \mathrm{C}\right]$} & {$[\mathrm{kg} / \mathrm{m} 3]$} & {$[\mathrm{kg} / \mathrm{m} 3]$} & {$[\mathrm{m} / \mathrm{s}]$} & {$[\mathrm{kJ} / \mathrm{kg}]$} & {$[\mathrm{kJ} / \mathrm{kg}]$} \\
\hline 1 & 3 & 120 & 90 & 943 & 965 & 2 & 504 & 377 \\
\hline 2 & 3 & 90 & 60 & 965 & 983 & 2 & 377 & 251 \\
\hline 3 & - & - & - & optional & - & - & - & - \\
\hline 4 & 2 & 160 & 90 & 1.16 & 965 & 30 & 2’790 & 377 \\
\hline 5 & 5 & 210 & 90 & 2.3 & 965 & 30 & 2'877 & 377 \\
\hline 6 & 21 & 270 & 90 & 8.9 & 965 & 30 & 2’949 & 377 \\
\hline
\end{tabular}

For the analysed case study, the total number of possible carrier fluids included in the model is 6 , consisting in water or steam at different thermodynamics conditions (Table 1). the fluid $f=3$ is optional and not considered in the decisional procedure; the fluid $f=6$ is treated separately, because it could be requested only by user $i=2$ for process needs, with a constant power request, and in this case a second steam extraction from turbine is requested and the performance calculation for this turbine includes a specific section.

The fluids and thermal users' constraints and value assignations, applied to the specific case study, are formalized below:

$\delta_{i, f}=0, f \in[3,6], i \in[5,9]$

$\delta_{i, 6}=0, \forall i \in\{1,3,4,5\}$

$\sum_{f=1}^{5} \delta_{i, f}=0, \forall i$

$\delta_{i, f}=0, f=3, \forall i$

\subsubsection{District heating network}

The District Heating (DH) network is defined by 8 main sections and 9 branches, among which only three of them are not negligible, as shown in Table 2 and Table 3.

Table 2. DH network main sections

\begin{tabular}{|r|c|c|c|c|c|c|c|c|}
\hline \multicolumn{1}{|c|}{1} & 2 & 3 & 4 & 5 & 6 & 7 & 8 \\
\hline SecD & SecD1 & SecD2 & SecD3 & SecD4 & SecD5 & SecD6 & SecD7 & SecD8 8 \\
\hline$[\mathrm{m}]$ & 110 & 180 & 179 & 240 & 509 & 282 & 39 & 45 \\
\hline
\end{tabular}

Table 3. DH network branches

\begin{tabular}{|r|c|c|c|c|c|c|c|c|c|}
\hline$i$ & 1 & 2 & 3 & 4 & 5 & 6 & 7 & 8 & 9 \\
\cline { 2 - 11 } SecL & SecL1 & SecL2 & SecL3 & SecL4 & SecL5 & SecL6 & SecL7 & SecL8 & SecL99 \\
\hline$[\mathrm{m}]$ & 240 & 90 & 0 & 0 & 0 & 0 & 0 & 0 & 45 \\
\cline { 2 - 10 } & & & & & & & &
\end{tabular}

\subsubsection{Thermal cycle and steam turbine.}

The reference values for the inlet conditions to the steam turbine are the following: inlet temperature $\mathrm{T}=465^{\circ} \mathrm{C}$, inlet pressure $\mathrm{p}=50 \mathrm{bar}$, maximum inlet mass flow rate $n \&$ equal to $5.8 \mathrm{~kg} / \mathrm{s}$. The maximum gross electrical power allowed by the Authorization is $5 \mathrm{MW}$.

The total number of turbines considered in the model, matching with these constraints, is 8 ; for each turbine mass and energy balances have been written, and the $8\left(P t_{B I O}, P e_{G R O}\right)$ curves have been plotted in Figure 1.

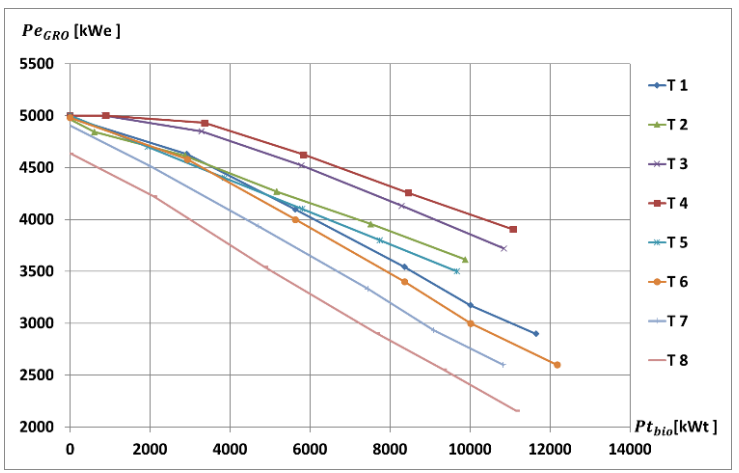


Figure 1. Turbines performance graph: gross electric power vs thermal power producible from the biomass cycle, for each steam turbine available

The constraints related the turbine choice are formalized below:

$$
\sum_{t=1}^{8} \tau_{t}=1
$$

$\sum_{t=7}^{8} \tau_{t}=\delta_{2,6}$

$\tau_{6} \geq\left(1-\delta_{2,6}\right) \sum_{i=1}^{9} \delta_{i, 5} / K$

$\tau_{1} \geq\left(1-\delta_{2,6}\right) \cdot\left(1-\tau_{6}\right) \cdot \sum_{i=1}^{9} \delta_{i, 4} / K$

where $\mathrm{K}$ is a dimensionless auxiliary parameter greater than 9 to formalize the constraints.

\subsection{Results}

Due to the wide number of possible configurations, a simplifying assumption has been done: since the civil users are all located very next to each other, they have been considered as a single user, adding the constraint: $\delta_{6, f}=\delta_{7, f}=\delta_{8, f}=\delta_{9, f}$

. With this assumption, the simulation elaborated 237'024 different configurations.

The maximum value of IRR results to be $26,88 \%$; comparing it with Required Rate of Return (RRR) reference values for this Project (about 12\%), or against usual rates of return in the securities market (minor than $4 \%$ ), the result is very positive.

If we compare the decisional variables and performance parameters values of the 20 highest IRR configurations, we can observe that all the industrial user (highest thermal request) are served by District Heating line; users 4 and 5 requested cooling energy; all the solution chose the steam turbine n. 4, the PES (Primary Energy Saving, see [9]) highest values almost match with highest IRR values.

Table 4 compares the main parameter values of the optimal solution with the corresponding minimum and maximum possible values.

Analysing the optimal solution, the most important observations are the followings.

The electric energy production is about the $84 \%$ of the total possible production (calculate as $5 \mathrm{MW}$ on $8000 \mathrm{~h}$ of biomass cycle operation), but the electric revenue represents the $94 \%$ of the maximum possible electric energy revenue. This means that the CAR prize operates a strong compensation in order to promote the production of electrical energy associated at higher cycle efficiency and Primary Energy Savings.

A sensitivity analysis over several fundamental parameters has been carried out, with the results plotted in Figure 2. The RRR value (12\%) of the IRR is reached in the following cases: by a biomass price increment of $75.5 \%$ (i.e. reaching a price per unit ton of about $80 € / \mathrm{t}$ ), by a biomass LHV reduction of $41.2 \%$, by an increment of the total hours of stop of the biomass cycle of $455.0 \%$ and by an average thermal tariff reduction of $64.7 \%$. The last two results are very important.
The first one means that a satisfactory value of IRR is maintained even if about the $60 \%$ of the total thermal energy initially considered is no more provided, possible scenario considering the significant difficulties of the Italian industrial sector.

Table 4. Optimal solution outputs compared with minimum and maximum values

\begin{tabular}{|c|c|c|c|c|}
\hline & m.u. & $\begin{array}{c}\text { Best } \\
\text { Solution }\end{array}$ & $\begin{array}{c}\text { Minimum } \\
\text { Value }\end{array}$ & $\underset{\text { Value }}{\text { Maximum }}$ \\
\hline \multicolumn{5}{|l|}{ PERFORMANCE DATA } \\
\hline PES & $\%$ & 26.0 & 0.0 & 26.0 \\
\hline CAR Prize & $€ / \mathrm{MWh}$ & 26.52 & 0.00 & 31.32 \\
\hline Gross El. Energy Production & $\mathrm{MWh} / \mathrm{y}$ & $33^{\prime} 695$ & $21^{\prime} 079$ & $40^{\prime} 000$ \\
\hline Th. Energy Request & $\mathrm{MWh} / \mathrm{y}$ & $93^{\prime} 015$ & 0 & $104^{\prime} 150$ \\
\hline Th. Energy by biomass & $\mathrm{MWh} / \mathrm{y}$ & $70^{\prime} 362$ & 0 & $79^{\prime} 518$ \\
\hline Th. Energy by Gas - Stops & $\mathrm{MWh} / \mathrm{y}$ & 3'957 & 0 & $4^{\prime} 984$ \\
\hline Th. Energy by Gas - Integr. & $M W h / y$ & $18^{\prime} 696$ & 0 & $24^{\prime} 645$ \\
\hline Biomass Consumption & ton & $57^{\prime} 403$ & $53^{\prime} 407$ & $57^{\prime} 447$ \\
\hline Gas Consumption & m3 & $2^{\prime} 520^{\prime} 390$ & 0 & $3^{\prime} 185^{\prime} 778$ \\
\hline \multicolumn{5}{|l|}{ INVESTMENTS COSTS } \\
\hline Steam Turbine & $€$ & $3^{\prime} 200^{\prime} 000$ & $2^{\prime} 100^{\prime} 000$ & $3^{\prime} 200^{\prime} 000$ \\
\hline DH Network & $€$ & $2^{\prime} 231^{\prime} 943$ & 0 & $5^{\prime} 308^{\prime} 846$ \\
\hline Gas Boilers & $€$ & $200^{\prime} 000$ & $200^{\prime} 000$ & $700^{\prime} 000$ \\
\hline Absorption Machines & $€$ & $720^{\prime} 000$ & 0 & $720^{\prime} 000$ \\
\hline \multicolumn{5}{|l|}{ OPERATING COSTS } \\
\hline Biomass cost & $€ / y$ & $2^{\prime} 728^{\prime} 014$ & $2^{\prime} 167^{\prime} 174$ & $2^{\prime} 730^{\prime} 227$ \\
\hline Natural Gas cost & $€ / y$ & $1^{\prime} 008^{\prime} 156$ & 0 & $1^{\prime} 274^{\prime} 311$ \\
\hline \multicolumn{5}{|l|}{ REVENUES } \\
\hline Thermal energy revenue & $€ / y$ & $6^{\prime} 095^{\prime} 156$ & 0 & $6^{\prime} 787^{\circ} 442$ \\
\hline Electric Energy revenue & $€ / y$ & $5^{\prime} 820^{\prime} 052$ & $3^{\prime} 629^{\prime} 578$ & $6^{\prime} 189^{\prime} 177$ \\
\hline
\end{tabular}

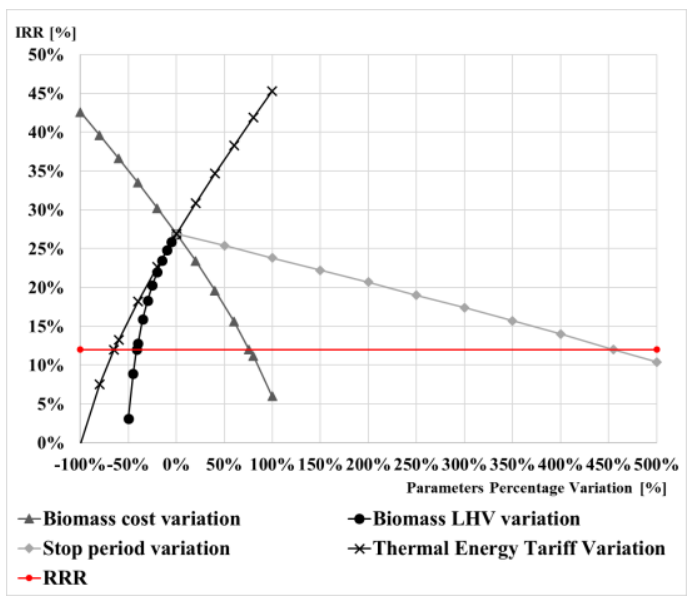

Figure 2. Sensitivity analysis of the IRR value

The second means that, with the mentioned reduction, the net thermal tariff respectively for industrial and civil users becomes about $29.52 € / \mathrm{MWh}$, that compared with a near $\mathrm{DH}$ service (Turin, April 2017) with an average tariff of about 80 $€ / \mathrm{MWh}$, lead the DH network a very competitive and affordable service while maintaining a satisfactory value of IRR.

\section{CONCLUSIONS}

The aim of this study is to create a Decision Support System for the evaluation of the sustainability of Biomass Combined Heat and Power (BCHP) Plants. A general approach to the problem has been adopted, which connects in the same model technical choices, performance calculation and cash flows optimization. 
The problem has been formalized in Excel Datasheets, considering the Due Diligence activities done with investors, thus choosing as decision variables the key parameters affecting the positive continuation of the Project; thus, an optimal solution which maximize the IRR (Internal Rate of Return of the Project) was found. Sensitivity analysis over the main stochastic parameters has been performed, and an interpretation analysis of the output data have been provided.

Among the analysis results, it is possible to deduce that the best values in term of the IRR are obtained with good turbine performance and great thermal energy request, even through additional investments (e.g. turbine or absorption machine costs). The sensitivity analysis revealed the solidity of the optimal solution and suggested strategies in the transactions with thermal users.

The present model could be an additional instrument for a useful comprehension, management and deeper analysis of the CHP Plant supplied by biomass with DH network integrated.

Moreover, the present study aims to be a useful contribution in the evaluation of a correct definition of National Incentives applied to these kind of plants, such as feed-in-premium tariff for electric energy or tax credit for thermal users served by biomass DH networks.

Several improvements and future developments could be suggested at least in three different directions. First, the integration of more accurate models related to the thermal cycle, plant components and DH design. Then, the progressive removal of constrains related to Authorized project, increasing the degrees of freedom (such as the plant size) and studying project at the feasibility study phase. Finally, the definition of a different objective function (to be minimized), representing not the return of the investment, but the risk in IRR variation by varying stochastic parameters during the Plant lifetime.

\section{ACKNOWLEDGMENTS}

Professor Antonella Priarone is greatly acknowledged for her helpful discussions and suggestions about this paper.

\section{REFERENCES}

[1] European Commission. (2014). European energy security strategy, Brussels, [COM (2014)330].

[2] European Commission. (2010). Energy 2020: A strategy for competitive, secure, and sustainable energy, Brussels, [COM (2010)639].

[3] European Commision. (2014). A policy framework for climate and energy in the period from 2020 to 2030, Brussels, [COM (2014)15].

[4] European Commision. (2011). Energy Roadmap 2050, Brussels, [COM (2011)885].

[5] MISE (2013). Italy's national energy strategy: for a more competitive and sustainable energy.

[6] MISE, Attuazione dell'art, 24 del decreto legislativo 3 marzo. (2011). N. 28, recante incentivazione della produzione di energia elettrica da impianti a fonti rinnovabili diversi dai fotovoltaici, (12A07628), GU Serie Generale n.159 del 10-7-2012 - Suppl. Ordinario No. 143.

[7] MISE Incentivazione dell'energia elettrica prodotta da fonti rinnovabili diverse dal fotovoltaico, (16A04832) (2016). GU Serie Generale n.150 del 29-6-2016.
[8] Lund H., Andersen A.N. (2005). Optimal designs of small CHP plants in a market with fluctuating electricity prices, Energy Convers. Manag, Vol. 46, pp. 893-904.

[9] MISE, Integrazioni al decreto legislativo 8 febbraio 2007, n. 20, di attuazione della direttiva 2004/8/CE sulla promozione della cogenerazione basata su una domanda di calore utile sul mercato interno dell'energia, e modificativa della direttiva 92/42/CE. (11A12046), GU Serie Generale n.218 del 19-9-2011. (Italian)

[10] Directive 2004/8/EC - Directive on the promotion of cogeneration based on a useful heat demand in the internal energy market (2004). European Parliament and the Council of the European Union.

[11] Ferreira A.C., Nunes M.L., Teixeira S., Martins L.B. (2014). Technical-economic evaluation of a cogeneration technology considering carbon emission savings, International Journal of Sustainable Energy Planning and Management, Vol. 2, pp. 33-46.

[12] Peters M.S., Timmerhaus K.D. (1991). Plant Design and Economics for Chemical Engineers, McGraw-Hill Book Co., Singapore.

[13] Bejan A., Tsatsaronis G., Moran M. (2004). Thermal and Design Optimization, John Wiley and Sons Inc, New York.

[14] Lazzaretto A., Toffolo A. Energy, economy and environment as objectives in multi-criterion optimization of thermal systems design, Energy, Vol. 29, pp. 1139-1157.

[15] Rajh B., Yin C., Samec N., Hriberšek M., Zadravec M. (2016). Advanced modelling and testing of a 13 MWth waste wood-fired grate boiler with recycled flue gas, Energy Conversion and Management, Vol. 125, pp. 230-241.

[16] Gebreegziabher T., Olajire O.A., Luk H.T., Lam T.Y.G., Zhang Y., Hui C.W. (2014). Design and optimization of biomass power plant, Chemical Engineering Research and Design, Vol. 92, pp. 1412 1427.

[17] Cimdina G., Veidenbergs I., Kamenders A., Ziemele J., Blumberga A., Blumberga D. (2014). Modelling of biomass cogeneration plant efficiency, Agronomy Research, Vol. 12, pp. 455-468.

[18] N. Shabani, T. Sowlati, A mixed integer non-linear programming model for tactical value chain optimization of a wood biomass power plant, Applied Energy, vol. 104, 353-361, 2013.

[19] Freppaz D., Minciardi R., Robba M., Rovatti M., Sacile R., Taramasso A. (2004). Optimizing forest biomass exploitation for energy supply at a regional level, Biomass and Bioenergy, Vol. 26, pp. 15-25.

[20] Ferreira A.C., Nunes M.L., Teixeira S., Barreiros M.L. (2014). Technical-economic evaluation of a cogeneration technology considering carbon emission savings, International Journal of Sustainable Energy Planning and Management, Vol. 2, pp. 33-46.

[21] Mohan T., El-Halwagi M.M. (2007). An algebraic targeting approach for effective utilization of biomass in combined heat and power systems through process integration, Clean Techn Environ Policy, Vol. 9, pp. 13-5.

[22] Voicu P., Dumitriu D. (2015). Technical - economic analysis and management of Chp Plants, International 
Conference on Management and Industrial Engineering, Bucharest 7, pp. 729-740.

[23] Tereshchenko T., Nord N. (2016). Energy planning of district heating for future building stock based on renewable energies and increasing supply flexibility Energy, Vol. 112, pp. 1227-1244.

[24] Delmastro C., Mutani G., Schranz L. (2015). Advantages of coupling a woody biomass cogeneration plant with a district heating network for a sustainable built environment: a case study in Luserna San Giovanni, Energy Procedia, Vol. 78, pp. 794-799.

[25] Sartor K., Quoilin S., Dewallef P. (2014). Simulation and optimization of a CHP biomass plant and district heating network, Applied Energy, Vol. 130, pp. 474483.

[26] Quattordio Combined Heat and Power Plant - Final Project Documents - Autorizzazione Unica n. DDAP1407/2012 (Italian).

\section{NOMENCLATURE}

$\mathrm{a}$

CASH

Coeff1

Coeff2

Coeff3

cold

COP

$\mathrm{cu}$

dmax

$\mathrm{Ee}$

EQU

Et

fmax

imax

h

h

IRR

$\mathrm{K}$

Lcum

$\mathrm{N}$

NPV

$\mathrm{p}$

$\mathrm{Pe}$

PES

$\mathrm{Pf}$ dimensionless parameter defining the $\mathrm{DH}$ network

Cash Flow term, $€$

quadratic curve coefficient 1 for the electric power calculation, $\mathrm{kW}-1$

quadratic curve coefficient 1 for the electric power calculation, dimensionless

quadratic curve coefficient 1 for the electric power calculation, $\mathrm{kW}$

dimensionless binary decisional variable

defining cooling energy request

Coefficient of Performance

DH cost per unit length of pipe, $€$. m-1

maximum value of subscript $d$

electric energy, MWh

Equity Funding term, $€$

thermal energy, MWh

maximum value of subscript $f$

maximum value of subscript $i$

enthalpy, kJ. kg-1. ${ }^{\circ} \mathrm{C}-1$

number of hours of the period, $h$

Internal Rate of Return, dimensionless

dimensionless auxiliary paramenter

cumulative length, $\mathrm{m}$

Net Cash Flow term

Net Present Value, $€$

Pressure, bar

electrical power, $\mathrm{kW}$

Primary Energy Saving

cooling power, $\mathrm{kW}$

$\mathrm{Pt} \quad$ thermal power, $\mathrm{kW}$

Pt' thermal power per unit length, W. m-1

SecD DH network main section lenght, $m$

SecL DH network branch lenght, $m$

$\mathrm{T} \quad$ Tariff (thermal or electrical), $€$. MWh-1

$\mathrm{T} \quad$ Temperature, ${ }^{\circ} \mathrm{C}$

TC tax credit, $€$. MWh-1

$\mathrm{v} \quad$ carrier fluid speed, $\mathrm{m}$. s-1

\section{Greek symbols}

$\delta$

$\pi$

$\rho$

$\tau$

\section{Subscripts}

base

$\mathrm{BIO}$

CAR

d

D

DEL

DH

el

$\mathrm{f}$

FIN

fix

GAS

GRO

STO

i

LOSS

$\mathrm{m}$

MAX

n

NET

OPE

pr1

pr2

pr3

RET

$\mathrm{t}$

th

TOT

$\mathrm{y}$ dimensionless binary decisional variable defining thermal users and fluids

diameter, $\mathrm{mm}$

dimensionless Greek pi number

density, kg. m-3

dimensionless binary decisional variable defining the steam turbine

base electrical tariff

biomass steam thermal cycle

High Efficiency CHP regulation

main section of DH network

daily, related to the year subdivision

delivery, related to the $\mathrm{DH}$ pipes

District Heating

electric

fluid

related to financial activities

fix value

natural gas

gross, related to electrical production

stop, related to biomass cycle stops

thermal user

related to thermal losses

period

maximum value

net value (thermal tariff)

net, related to related to electrical production

related to operating activities

electric energy prize 1

electric energy prize 2

electric energy prize 3

return, related to the $\mathrm{DH}$ pipes

turbine

thermal

total value

year 